\title{
Fungal Infections in HIV-positive Peruvian Patients: Could the Venezuelan Migration Cause a Health Warning Related-infectious Diseases?
}

\author{
Jeel Moya-Salazar ${ }^{1,2 *}$, Richard Salazar-Hernández ${ }^{3}$, Victor Rojas-Zumaran², Wanda C. Quispe ${ }^{3}$ \\ 'School of Medicine, Faculties of Health Science, Universidad Privada Norbert Wiener, Lima, Peru \\ ${ }^{2}$ Pathology Department, Hospital Nacional Docente Madre Niño San Bartolomé, Lima, Peru \\ ${ }^{3}$ Cytopathology and Genetics Service, Department of Pathology, Hospital Nacional Guillermo Almenara Irigoyen, Lima, Peru
}

Article Info

\section{Article Notes}

Received: December 22, 2018

Accepted: March 7, 2019

\section{*Correspondence:}

Jeel Moya-Salazar, M.T, M.Sc., 957 Pacific Street, Urb. Sn

Felipe, 07 Lima, Lima 51001, Peru; Telephone No: +51 986014-954; Email: jeel.moyasalazar@icloud.com.

(c) 2019 Moya-Salazar J. This article is distributed under the terms of the Creative Commons Attribution 4.0 International License.

\section{Keywords}

Human-immunodeficiency virus

Mycosis

Candidiasis

Pneumocystis pneumonia

Cryptococcosis

Highly Active Antiretroviral Therapy

\section{Abstract}

In patients with human immunodeficiency virus (HIV), opportunistic infections occur that could compromise the health of patients. In order to determine the frequency of fungal opportunistic and superficial infections in HIV-positive men-who-have-sex-with-men (MSM) patients at the Hospital Nacional Guillermo Almenara, we conducted a cross-sectional retrospective study. We include Peruvian patients $>18$ years-old, derived from infectious or gynecological offices, with or without antiretroviral treatment.

One hundred thirteen patients were enrolled $(36.7 \pm 10$, range: 21 to 68 years), which $46(40.7 \%)$ has an opportunistic fungal infection, mainly by candidiasis $(23.9 \%)$, pneumocystosis $(8.7 \%)$, and cryptococcosis $(6.5 \%)$. Six (13\%) patients had fungal coinfections, mainly by oral candidiasis and ringworm (Tinea pedis) (4.3\%), and opportunistic infections have an incidence of $15.9 \%$. Of the 17 cases of dermatophytosis, 12 (70.6\%) were from Tinea pedis, 5 (29.4\%) from Tinea corporis, 3 (17.6\%) from Tinea unguium, and two (11.8\%) from Tinea versicolor. We found significant difference between the year of HIV-infection and the year of fungal infection $(p=0.001)$.

The frequency of opportunistic fungal infections was determined in the fourth-and-six percent of Peruvian MSM HIV-positive patients, where candidiasis, pneumocystosis, and cryptococcosis were the most frequent. We raise the importance of fungal infections in the current framework of Venezuelan migration, since this could be a new risk factor and imply changes in incidence rates, which implies new challenges for Peruvian Public Health.

\section{Introduction}

Duringthe developmentofinfectionbythehumanimmunodeficiency virus (HIV), opportunistic infections occur that can compromise the health of patients. The main opportunistic infections are filamentous fungi and yeast. In the United States (US), 14\% of patients with HIV have opportunistic fungal invasive infections, while in low-and-middleincome countries in Latin America; fungal infections affect 1.6 million patients with unpredictable degrees of severity ${ }^{1,2}$.

Globally the main opportunistic fungi are Cryptococcus neoformans var neoformans (cryptococcosis), Pneumocystis jirovecii (pneumocystosis), Histoplasma capsulatum (histoplasmosis), and Candida albicans (candidiasis) ${ }^{3,4}$. In Latin America, paracoccidioidomycosis (Paracoccididoides brasiliensis) is added as clinically significant endemic mycoses, while in Peru, candidiasis, aspergillosis (Aspergillus fumigatus), and pneumocystosis have been reported as the major fungal diseases, affecting $\sim 1.9 \%$ of the Peruvian population ${ }^{5}$.

The maintenance of opportunistic fungal infections depends on several factors such the type of High- antiretroviral treatment 
(HAART), social determinants, poor sanitary maintenance, migrations and conventional evolutionary determinants for the distribution and fixation of infections, endemic diseases that affect the vulnerable territory, men-whohave-sex-with-men (MSM) and women-who-have-sexwith-women (WSW), among others ${ }^{3-9}$.

We aimed to determine the frequency of opportunistic and superficial fungal infections in HIV-positive patients at the Guillermo Almenara Irigoyen National Hospital (HNGAI) included in the anal cancer-screening program for MSM/WSW (PDCA-HSH/MSM). We also propose a discussion of the perspectives on HIV-infections in the current framework of the Venezuelan migration since this implies new challenges for the Peruvian Public Health.

\section{Methods}

\section{Patients}

We conducted a retrospective cross-sectional study at the HNGAI in Lima, Peru during 2018. We were included male patients $\geq 18$ years, with or without HAART, from all regions of Peru, and derived from the infectiology or gynecological offices. Clinical characteristics and risk factors of these patients reported during the interview at clinical admission or infectious-follow-up were considered. The Ethics Committee, Research Committee, and Hospital Administration approved this study (072-CIEI-OCID-G-HNGAI-ESSALUD-2018).

\section{Clinical and microbiological aspects}

HIV's determination was carried out in accordance with the standardized protocols of the Social Security of Peru (EsSalud) and the international guidelines ${ }^{10,11}$. Patients were referred from primary-care centers to HNGAI for diagnostic confirmation of HIV. The stage of HIV infection was stratified, and HAART was started according to the national clinical guidelines ${ }^{12}$. When patients presented symptoms related to fungal infection or adverse reactions to treatment, we were requested profiles through the appropriate medical consultation including microbiological, immunological and biochemical. Opportunistic infection was determined in this way, first by routine mycological methods, as bright-field microscopy, manual culture and biochemical tests ${ }^{13}$, then with the automated system Vitek ${ }^{\circledR} 2$ Compact (BioMérieux, Marcy-l'Étoile, France).

\section{Data analysis}

We performed a structured review of the patient's medical records, where we considered the following data: age, sex, viral load (with real-time polymerase chain reaction test (RT-PCR), cut-off limit 50 copies/ml), CD4+ lymphocyte level (with flow-cytometry), stage and time of HIV infection, and HAART scheme ${ }^{14}$.

The time of infection between the confirmatory diagnosis of HIV and fungal infection is the time (in years) after the confirmatory diagnosis and onset of HAART until the diagnosis of fungal infection (with microbiological tests). We use the international disease code (CIE) for the inclusion and coding of medical records data (CIE: B24.X for HIV, and CIE: B35 to B49 for fungal infections).

We used descriptive statistics and simple frequencies. In addition, we used the Pearson test and one-way ANOVA considering a confidence interval of $95 \%$ (95\% CI) and a p-value $<0.05$ as statistically significant. The statistical analyzer used was SPSS v21.0 (IBM, Armonk, USA) and BoxPlotR (Tyers and Rappsilber labs, Edinburg, UK) for Chrome® (Google, CA, USA).

\section{Results}

One hundred thirteen HIV-positive patients were included with an average age of $39.1 \pm 12$ years (95\% CI: 36.9 to 41.3 ). The age range was between 19 and 69 years. We report patients in HIV-status of infection A1 (4 subjects, 3.5\%), A2 (15 subjects, $13.3 \%$ ), A3 (14 subjects $12.4 \%$ ), then B1 (4 subjects, $3.5 \%$ ), B2 (13 subjects, $11.5 \%$ ), and B3 (seven subjects, 6.2), and, finally, C1 (3 subjects, 2.7\%), C2 (one subject, $0.9 \%$ ), and C3 (43 subjects, 38.1\%). Likewise, nine (8\%) patients had an unspecified stage of infection (Figure 1).

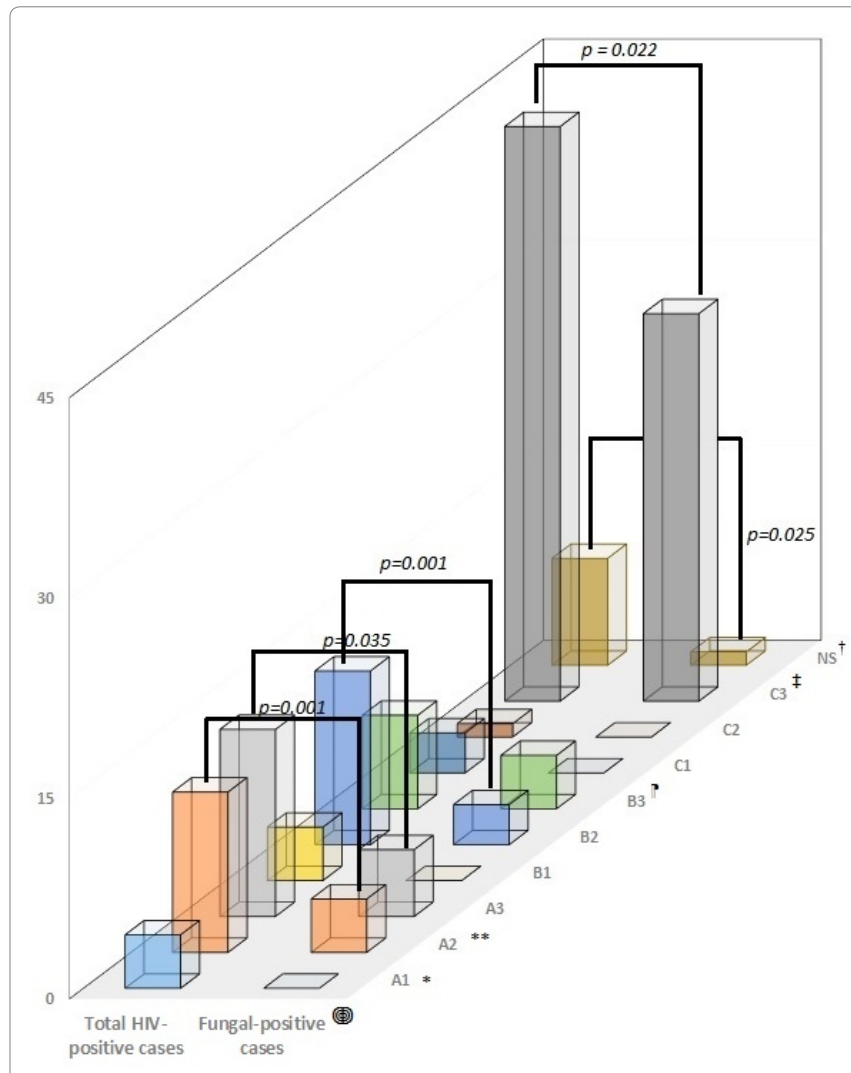

Figure 1: Distribution of the total cases of HIV-positive and with fungal infections. We note the significant differences according to the status of the infection between both groups (see $p$ values). Difference between both groups $(p<0.05)$. *Difference between group $A(p<0.05)$. **Differences between group $A$ and $C(p=0.007)$. "Difference between group $B(p=0.012)$. "Difference between group $C(p=0.001)$. ${ }^{+}$Non-difference the NS group and the other groups ( $p>0.05)$. Abbreviations: NS: unspecified 
We found significant difference between the years of the HIV-patients with fungal infection versus the uninfected $(\mathrm{p}=0.048)$.

According to the biological characteristics, the average level of CD4+ lymphocytes was $384.4 \pm 242$ cells $/ \mathrm{ml}$ (95\% CI: 340 to 429 ) with a minimum count of 15 cells $/ \mathrm{ml}$ and a maximum of 1109 cells $/ \mathrm{ml}$. The average viral load was $144890 \pm 78595.2$ copies/RNA (95\% CI: 398.4 to 29380.4 ) with a range of undetectable to 655 thousand copies/ RNA (Figure 2). We did not find an association between fungal infection and CD4+ lymphocyte level $(\mathrm{p}=0.405)$ nor with viral load $(\mathrm{p}=0.552)$.

In total, we determined 46 (40.7\%) patients with fungal infections (Table 1). The mean HIV-infection diagnosis year was $2006 \pm 6.5$ years (range: 1990-2017). Since the first infection and the confirmatory diagnosis of HIV infection, the average number of years until the fungal infection was $3.6 \pm 3.8$ years ( $95 \% \mathrm{CI}$ : 2.4 to 4.8$)$.

The most frequent fungal opportunistic infections were candidiasis with 11 patients $(23.9 \%)$, pneunomcystosis with four patients (8.7\%), and cryptococcosis with three patients (6.5\%). This indicates an incidence of opportunistic infections $15.9 \%$. The most frequent superficial fungal infections were Tinea pedis with 12 patients $(26.1 \%)$, Tinea corporis with 5 patients $(10.9 \%)$, Tinea unguium (onychomycosis) with 3 patients $(6.5 \%)$, and Tinea versicolor (Pityriasis versicolor) with 2 patients (4.3\%) (Figure 3).

Six (13\%) HIV-positive patients had fungal coinfections. The most common coinfections were candidiasis oral and ringworm (Tinea pedis) (4.3\%, two patients). The average of CD4+ lymphocyte level was $227 \pm 242$ cells / $\mathrm{ml}$, and the time of fungal infection was $4.3 \pm 4.7$ years. We did not found differences between the time of fungal co-infections and single infections $(\mathrm{p}=0.242)$.

Of the eleven cases of candidiasis, two (18.2\%) correspond with candidal balanitis, three $(27.3 \%)$ with candidal stomatitis, two (18.2\%) with oral candidiasis, three (27.3\%) with esophageal candidiasis, and one (9.1\%) with brachial candidiasis. These patients had an average age of $42 \pm 11.2$ years, a mean CD4+ lymphocyte count of $281.1 \pm 138$ cells, and an average of $2.32 \pm 3$ years between the diagnosis of HIV and candidiasis. None of the patients diagnosed with Candidiasis presented the same HAART.

In the HIV-Associated pneumocystis pneumonia patients $(n=4)$, the average age was $38.5 \pm 8.5$ years, a mean CD4+ lymphocyte count of $322.5 \pm 212$ cells $/ \mathrm{ml}$, and an average of $4.7 \pm 5.7$ years between the diagnosis of HIV and pneumonia. Three of these patients were in stage C3 and one in $\mathrm{A} 3$.

In the three cases of cerebral cryptococcosis, the average age was $38.3 \pm 3.2$ years and the time between the diagnosis
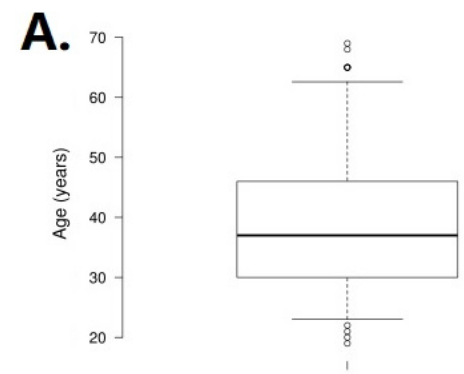

HIV-positive patients
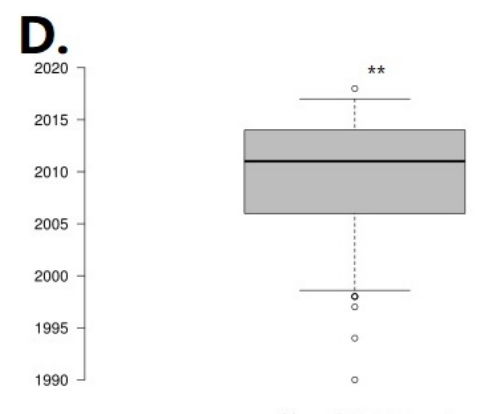

Year of HIV diagnosis
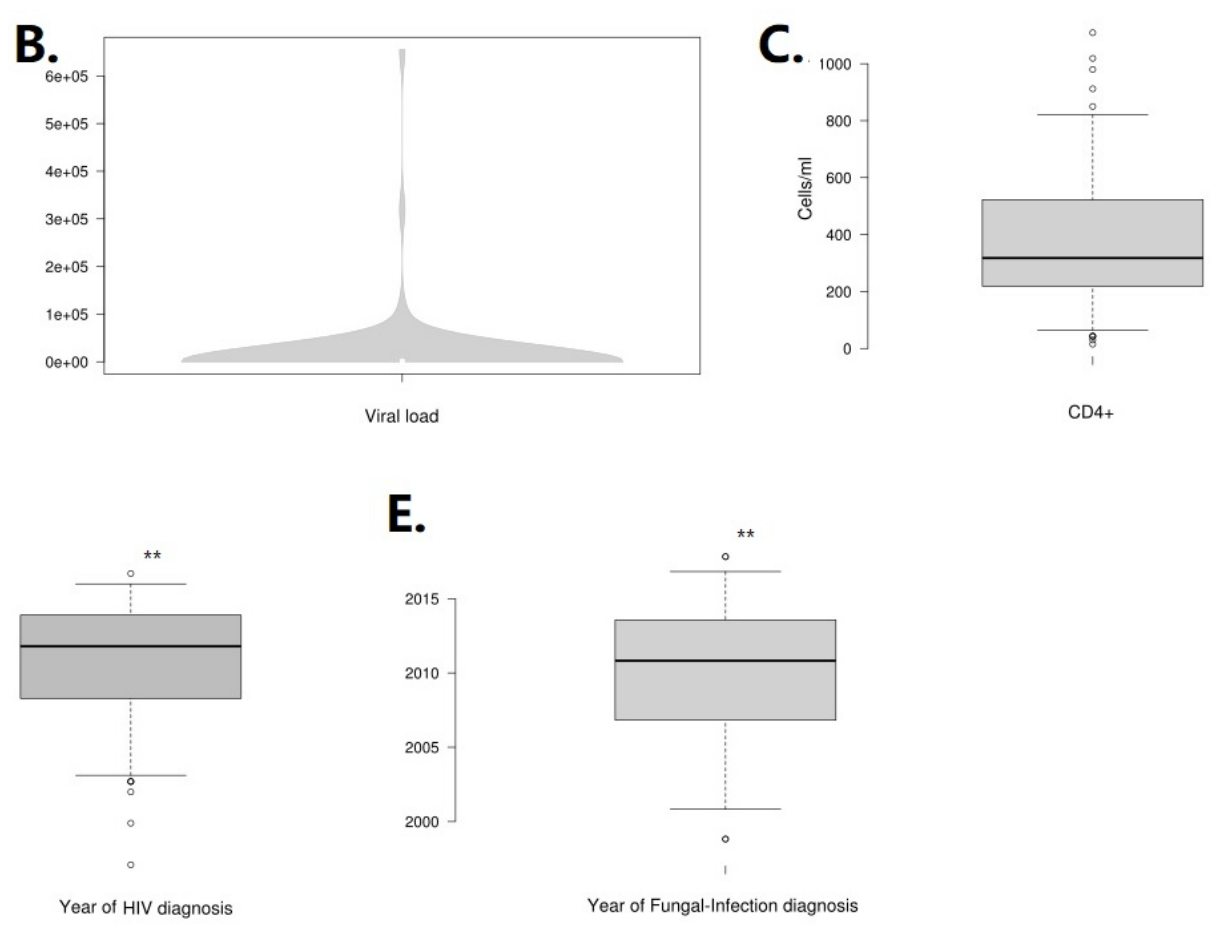

Figure 2: Distribution of clinical outcomes of HIV-positive patients. In A, the distribution of the age of patients is show, whilst in B (viral load in violplot) and $\mathbf{C}$ shows the immunological characteristic of the patients. In D and $\mathbf{E}$, we show and compare means of year of HIVdiagnosis and Fungal-infection diagnosis. ${ }^{* *}(\mathrm{p}=0.001)$. 
Table 1: Summary of Peruvian HIV-positive fungal-infections patients $(n=46)$.

\begin{tabular}{|c|c|c|c|c|c|c|c|c|}
\hline № & Fungal infection & Age & $\begin{array}{c}\text { HIV } \\
\text { Status } \\
\end{array}$ & $\begin{array}{c}\text { Year of } \\
\text { diagnosis* }\end{array}$ & Current HAART scheme and others** & $\begin{array}{c}\text { CD4 } \\
(\mathrm{cel} / \mathrm{ml})^{\S}\end{array}$ & $\begin{array}{c}\text { CV } \\
\text { [copies] } / \mathrm{ml}^{\S}\end{array}$ & $\begin{array}{c}\text { Infection time } \\
\text { (years) }^{\ddagger}\end{array}$ \\
\hline 1 & $\begin{array}{l}\text { Cryptococcosis } \\
\text { Ringworm (Tinea pedis) }\end{array}$ & 45 & $\mathrm{C} 3$ & 1994 & $\mathrm{EFV}(3)+\mathrm{AZT}(6)+3 \mathrm{TC}(2)$ & 198 & 0.1 & 21 \\
\hline 2 & Ringworm (Tinea cruris) & 21 & B2 & 2015 & $E F V(1)+T P V(1)+3 T C(2)$ & 420 & 0.1 & 2 \\
\hline 3 & $\begin{array}{l}\text { Oral Candidiasis } \\
\text { Ringworm (Tinea pedis) }\end{array}$ & 27 & B3 & 2006 & $E F V(3)+A B C(2)+3 T C(2)$ & 540 & 0.1 & 11 \\
\hline 4 & Tinea unguium (onychomycosis) & 41 & $\mathrm{~A} 2$ & 2012 & $\operatorname{TVD}(1)+\mathrm{MK}(2)+\mathrm{MK}(1)$ & 43 & 300 & 6 \\
\hline 5 & Cerebral cryptococcosis & 37 & $\mathrm{C} 3$ & 2001 & $\mathrm{PI} / \mathrm{r}(4)+\mathrm{RIT}(2)+\mathrm{RAL}(2)+\mathrm{ETV}(4)$ & 320 & 0.1 & 15 \\
\hline 6 & Oral Candidiasis & 37 & $\mathrm{C} 3$ & 2009 & INH (3) + RTV (2) & 450 & 0.1 & 8 \\
\hline 7 & Candidal balanitis & 29 & $\mathrm{~A} 2$ & 2012 & $\mathrm{TDF} / \mathrm{FTC}(1)+\mathrm{EFV}(1)$ & 230 & $-\S$ & 6 \\
\hline 8 & Ringworm (Tinea corporis) & 25 & $\mathrm{NE}$ & 2014 & TDF (1) +EFV/ddC (1) & - & - & 4 \\
\hline 9 & Esophageal candidiasis & 44 & $\mathrm{C} 3$ & 2002 & $\operatorname{EFV}(1)+3 T C(2)+\operatorname{TDF}(1)$ & 171 & 0.1 & 15 \\
\hline 10 & Tinea unguium (onychomycosis) & 36 & $\mathrm{C} 3$ & 2014 & $\operatorname{EFV}(1)+\operatorname{TDF}(1)+3 \mathrm{TC}(2)$ & - & - & 3 \\
\hline 11 & Brachial candidiasis & 49 & B2 & 1990 & $E F V(3)+A B C(2)+3 T C(2)$ & - & - & 25 \\
\hline 12 & Ringworm (Tinea pedis) & 57 & $\mathrm{~A} 3$ & 1997 & $\operatorname{EFV}(1)+\operatorname{TFV}(1) / F T C(1)$ & 540 & 0.1 & 19 \\
\hline 13 & $\begin{array}{l}\text { Ringworm (Tinea pedis) } \\
\text { Oral Candidiasis }\end{array}$ & 39 & $\mathrm{C} 3$ & 2013 & $\operatorname{TFV}(1)+3 \operatorname{TC}(2)+\mathrm{KAL}(14)+\mathrm{RAL}(2)$ & 310 & 0.1 & 3 \\
\hline 14 & Ringworm (Tinea pedis) & 28 & $\mathrm{C} 3$ & 2002 & $\mathrm{EFV}(3)+\mathrm{AZT}(6)+\mathrm{ddl}(4)$ & 350 & 0 & 2 \\
\hline 15 & Pneumocystis pneumonia & 45 & $\mathrm{C} 3$ & 2014 & $\mathrm{EFV}(1)+\operatorname{TDF}(1)+3 \mathrm{TC}(2)$ & 220 & 0 & 1 \\
\hline 16 & Candidal stomatitis & 37 & $\mathrm{C} 3$ & 2010 & $\mathrm{~d} 4 \mathrm{~T}(2)+\mathrm{EFV}(2)+\mathrm{LPV} / \mathrm{r}(4)$ & 423 & 399 & 4 \\
\hline 17 & Ringworm (Tinea pedis) & 26 & $\mathrm{C} 3$ & 1999 & $\operatorname{EFV}(1)+\operatorname{TDF}(1)+3 \mathrm{TC}(2)$ & 441 & 483 & 7 \\
\hline 18 & Ringworm (Tinea corporis) & 50 & $\mathrm{C} 3$ & 1999 & $\mathrm{~d} 4 \mathrm{~T}(2)+\mathrm{ddl}(4)+\mathrm{NFV}(10)$ & 358 & 40521 & 4 \\
\hline 19 & Ringworm (Tinea corporis) & 40 & $\mathrm{C} 3$ & 2008 & $A Z T(4)+3 T C(2)+K A L(4)$ & 254 & 2156 & 2 \\
\hline 20 & Ringworm (Tinea pedis) & 65 & B3 & 2002 & $\mathrm{EFV}(3)+\mathrm{AZT}(6)+3 \mathrm{TC}(2)+\mathrm{KAL}(8)$ & 850 & 130 & 0 \\
\hline 21 & Oral Candidiasis & 46 & $\mathrm{C} 3$ & 2010 & $A B C(2)+3 T C+E F V(1)$ & 230 & 1900 & 0 \\
\hline 22 & $\begin{array}{l}\text { Cerebral cryptococcosis } \\
\text { Brachial candidiasis }\end{array}$ & 42 & A3 & 2007 & $A B C(2)+3 T C(2)+A Z T(2)$ & 42 & 20542 & 1 \\
\hline 23 & Cerebral cryptococcosis & 42 & $\mathrm{C} 3$ & 2000 & $A Z T(6)+A B C(2)+3 T C(2)+K A L(6)$ & 30 & 1500 & 11 \\
\hline 24 & Tinea versicolor (Pityriasis versicolor) & 59 & B3 & 1998 & $\mathrm{EFV}(1)+3 \mathrm{TC}(2)+\mathrm{ATZ}(2)+\mathrm{RIT}(2)$ & 715 & 882 & 15 \\
\hline 25 & Ringworm (Tinea pedis) & 57 & $\mathrm{C} 3$ & 2012 & $A Z T(6)+3 T C(2)+E F V(3)$ & 253 & 74265 & 1 \\
\hline 26 & Tinea unguium (onychomycosis) & 34 & $\mathrm{C} 3$ & 2007 & $\mathrm{EFV}(1)+\mathrm{ABC}(2)+3 \mathrm{TC}(2)$ & 15 & 104666 & 5 \\
\hline 27 & Ringworm (Tinea cruris) & 69 & $\mathrm{C} 3$ & 2000 & $\mathrm{APV}(1)+\mathrm{d} 4 \mathrm{~T}(1)+3 \mathrm{TC}(1)$ & 341 & 0 & 11 \\
\hline 28 & Ringworm (Tinea corporis) & 53 & $\mathrm{C} 3$ & 2007 & $E F V(3)+A Z T(4)+3 T C(2)$ & 360 & 0 & 4 \\
\hline 29 & Pneumocystis pneumonia & 37 & $\mathrm{~A} 3$ & 2000 & $\mathrm{RAL}(2)+\mathrm{RIT}(4)+\mathrm{EFV}(1)$ & 182 & 0 & 13 \\
\hline 30 & Ringworm (Tinea pedis) & 37 & $\mathrm{~A} 3$ & 2015 & $\operatorname{TDF}(1)+3 \operatorname{TC}(2)+\operatorname{EFV}(1)$ & 251 & 547 & 2 \\
\hline 31 & Ringworm (Tinea pedis) & 65 & $\mathrm{C} 3$ & 2014 & $\operatorname{TDF}(1)+3 \operatorname{TC}(2)+\mathrm{KAL}(6)$ & 328 & 166 & 3 \\
\hline 32 & Esophageal candidiasis & 25 & $\mathrm{C} 3$ & 2010 & $3 \mathrm{TC}(2)+\operatorname{EFV}(1)+\operatorname{TDF}(1)$ & 44 & 319369 & 1 \\
\hline 33 & Pneumocystis pneumonia & 27 & $\mathrm{C} 3$ & 2014 & $\operatorname{EFV}(1)+\operatorname{TDF}(1)+3 \mathrm{TC}(2)$ & 250 & 554 & 1 \\
\hline 34 & Ringworm (Tinea pedis) & 65 & $\mathrm{C} 3$ & 1998 & $\mathrm{AZT}(3)+\mathrm{RIT}(8)+\mathrm{SQV}(6)$ & 199 & 399 & 3 \\
\hline 35 & Ringworm (Tinea pedis) & 56 & $\mathrm{~A} 3$ & 2011 & $\mathrm{EFV}(3)+\mathrm{AZT}(6)+3 \mathrm{TC}(2)$ & 551 & 0 & 1 \\
\hline 36 & Pneumocystis pneumonia & 45 & $\mathrm{C} 3$ & 2006 & $\mathrm{EFV}(3)+\mathrm{d} 4 \mathrm{~T}(1)+3 \mathrm{TC}(1)$ & 638 & - & 4 \\
\hline 37 & Cryptococcosis & 36 & $\mathrm{C3}$ & 2015 & $\operatorname{EFV}(1)+\operatorname{TDF}(1)+3 \mathrm{TC}(2)$ & 300 & 50 & 1 \\
\hline 38 & $\begin{array}{l}\text { Esophageal candidiasis } \\
\text { Oral Candidiasis }\end{array}$ & 32 & $\mathrm{C} 3$ & 2010 & $A Z T(6)+3 T C(2)+E F V(3)$ & 389 & 64 & 0 \\
\hline 39 & Candidal stomatitis & 61 & $\mathrm{C} 3$ & 2007 & $\mathrm{EFV}(3)+\mathrm{AZT}(4)+\mathrm{ddl}(4)$ & 445 & 0 & 0 \\
\hline 40 & Candidal stomatitis & 52 & B3 & 1999 & $\mathrm{EFV}(3)+\mathrm{AZT}(6)+3 \mathrm{TC}(2)$ & 179 & 399 & 0 \\
\hline 41 & Candidal balanitis & 52 & $\mathrm{~A} 2$ & 2017 & $A B C(2)+3 T C(2)+A Z T(2)$ & 250 & 885 & 1 \\
\hline 42 & Tinea unguium (onychomycosis) & 32 & $\mathrm{C3}$ & 2008 & $\mathrm{EFV}(1)+\mathrm{AZT}(6)+3 \mathrm{TC}(2)$ & 115 & 0 & 2 \\
\hline 43 & Ringworm (Tinea pedis) & 65 & B2 & 2011 & $\mathrm{EFV}(3)+\mathrm{d} 4 \mathrm{~T}(1)+3 \mathrm{TC}(1)$ & 250 & - & 0 \\
\hline 44 & Ringworm (Tinea pedis) & 39 & C3 & 2007 & $\mathrm{EFV}(3)+\mathrm{ABC}(2)+3 \mathrm{TC}(2)$ & 450 & - & 5 \\
\hline 45 & $\begin{array}{l}\text { Pneumocystis pneumonia } \\
\text { Candidal stomatitis }\end{array}$ & 43 & $\mathrm{C} 3$ & 2011 & $\operatorname{TDF}(3)+A Z T(6)+3 T C(2)$ & 74 & 7000 & 1 \\
\hline 46 & Ringworm (Tinea pedis) & 29 & $\mathrm{~A} 2$ & 1999 & $\mathrm{EFV}(3)+\mathrm{AZT}(6)+3 \mathrm{TC}(2)$ & 629 & 25570 & 8 \\
\hline
\end{tabular}

*Confirmatory diagnosis year of HIV infection. ${ }^{* *}$ Includes other treatments (e.g. TB). §CD4+ lymphocytes and viral load status when they had fungal infection. ¥Time between diagnosis and fungal infection. §Data not available. Abbreviations: CD4: CD4+lymphocyte count, CV: viral load, EFV: efenovir, APV amprenavir, AZT: azidovuline, 3TC: lamivudine, ABC: abacavir, NFV: nelfinavir, TPV: tipranavir, LPV/r: lopinavir/ritonavir, d4T: stavudine, RAL: raltegravir, ETV: etravirine, RTV: ritonavir, FTC: emtricitabine, ddl: didanosine, ddC: zalcitabine, TDF: tenofovir, KAL: Iopinavir, MK: MK-8591, PI/r: ritonavir-boosted protease inhibitor, SQV: saquinavir, RIT: radioimmunotherapy, INH: isonicotinylhydrazide, HAART: Highly active antiretroviral therapy.

of HIV and fungal infections was $5.3 \pm 5$ years. Likewise, all of $216 \pm 162$ cells $/ \mathrm{ml}$, and all were HIV-positive patients in of these patients had an average CD4+ lymphocyte count stage C3. None of the treatments was repeated. 


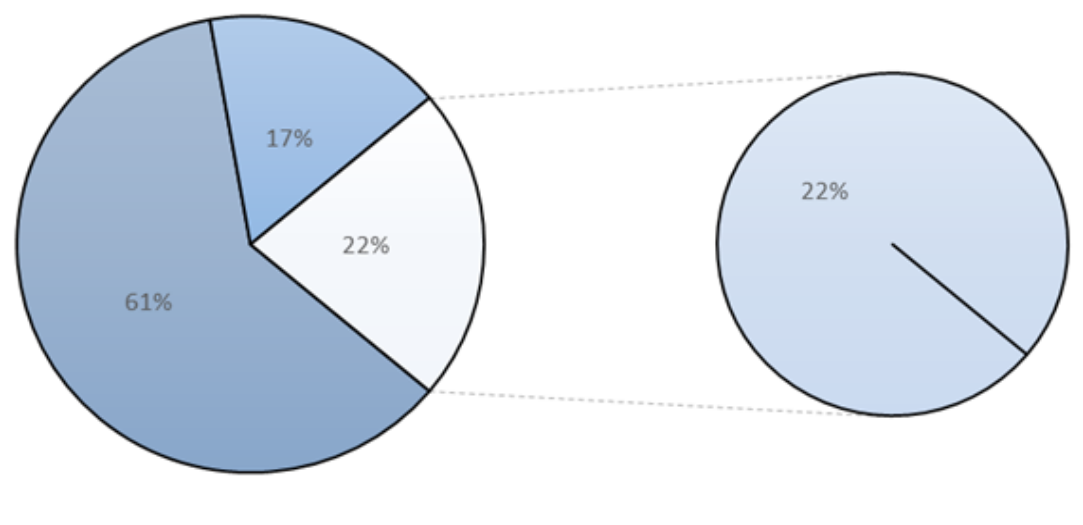

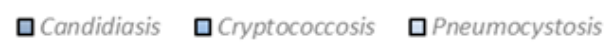

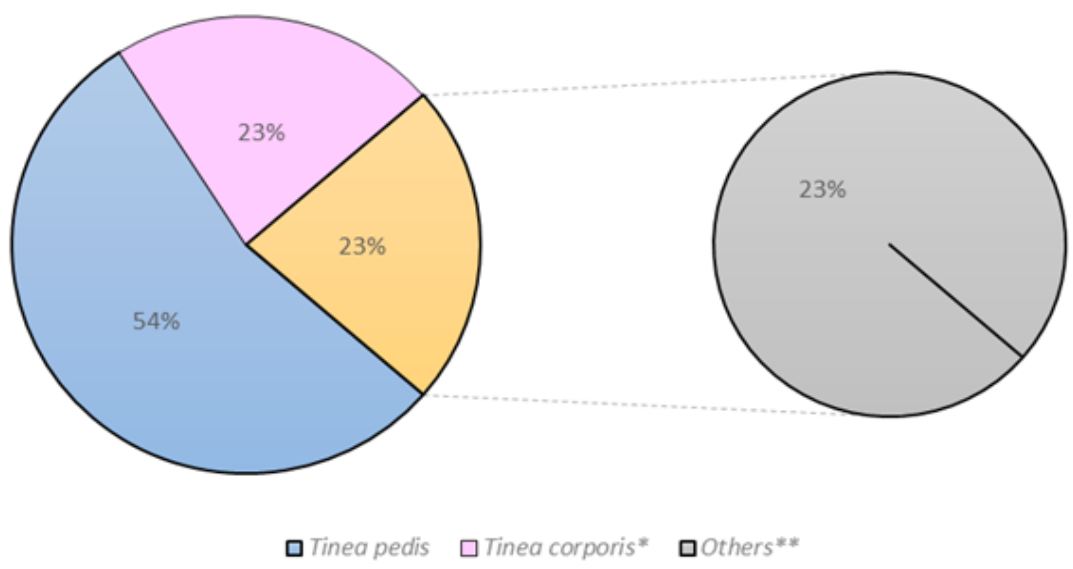

Figure 3: Distribution of opportunistic and superficial fungal infections in Peruvian HIV-positive patients. ${ }^{* *}$ Note that three patients had fungal coinfections. Data in \%

We found significant difference between the year of HIV-infection and the year of fungal infection $(p=0.001)$. Our data did not show significant differences between the ages of the patients according to HIV status ( $p=0.931)$, neither with the values of CD4+ lymphocytes according to the patient's disease status $(p=0.340)$. HAART did not correlate with patients with fungal infections $(\mathrm{p}=0.238)$.

Of the 17 cases of dermatophytosis, 12 (70.6\%) were from Tinea pedis, 5 (29.4\%) from Tinea corporis, 3 (17.6\%) from Tinea unguium, and two $(11.8 \%)$ from Tinea versicolor. The average age of patients with Tinea pedis was $47 \pm 15.3$ years. These presented a mean of $3 \pm 2.9$ years between the diagnosis of HIV and fungal infections, and an average of CD4+ lymphocyte count of $426 \pm 217$ cells/ $\mathrm{ml}$. The treatment of two (16.7\%) patients was repeated with EFV (3) + AZT (6) + 3TC (2) [efavirenz + zidovudine + lamivudine], and 5 (41.7\%) of them were C3, and $3(25 \%)$ were A3.

The other dermatophytoses had an average age of $46.7 \pm 17.7$ years for Tinea corporis, $34 \pm 2$ years for Tinea unguium, and $42 \pm 24$ years for Tinea versicolor; where the average age between HIV-diagnosis and infection was $4.4 \pm$
3.9 years, $2.6 \pm 2$ years, and $8.5 \pm 9$ years, respectively. The average of CD4+ lymphocyte count in Tinea corporis was $347 \pm 59.7$ cells $/ \mathrm{ml}$, for Tinea unguium was $65 \pm 70$ cells $/ \mathrm{ml}$, and for Tinea versicolor of $484 \pm 326$ cells $/ \mathrm{ml}$. Of the 5 Tinea corporis, two were Tineas cruris (inginal). The affectation according to the stage of the HIV disease was only one case of $\mathrm{B} 2$ and four of $\mathrm{C} 3$ for Tinea corporis, and all the cases of Tinea unguium and Tinea versicolor were $\mathrm{C} 3$.

HAART was heterogeneous among patients with and without fungal infection, however, nine patients $(8 \%)$ had the scheme EFV (1) + tenofovir [TDF] (1) + 3TC (2), followed of the scheme AZT (6) + 3TC (2) + EFV (3) with four (3.5\%) cases, and abacavir [ABV] (2) + 3TC (2) + AZT (2) with $3(2.7 \%)$ cases.

\section{Discussion}

This study showed that more than a quarter of Peruvian HIV-positive patients had fungal infections in a period of $\sim 3.6$ years of HIV infection, mainly for Candida and dermatophytes. Opportunistic infections had an incidence of $15.9 \%$, and significate differences were found in the time between the baseline HIV-infection and the years of fungal infection. 
In the US, candidiasis is the most frequent invasive fungal infection (55\%) followed by cryptococcosis $(25 \%)^{1}$. candidiasis affects more than 10 million people worldwide and compromises around 700 thousand cases of HIV patients, mainly as invasive infections ${ }^{15}$. candidiasis has increased progressively during the last two decades, being considered the most frequent invasive infection. This nosocomial infection represents a challenge for patients with HIV due to the complications that this may cause and the emerging rates of antifungal resistance ${ }^{16}$.

The epidemic rates of mycosis in these patients annually estimate 950 thousand cases of cryptococcosis, 400 thousand cases of pneumocystosis, and 300 thousand of disseminated histoplasmosis ${ }^{4}$. These three agents have been responsible for opportunistic infections in patients with HIV infection during the last five decades ${ }^{17,18}$. Our results agree, although not in that order, with opportunistic infections due to pneumocystis, and cryptococcosis, that represents the main cause of complications and mortality in seropositive patients, mainly in low-income countries ${ }^{19}$. In addition, our results highlight the large number of infections caused by Candida species.

MSM are up to 28 times more likely to acquire HIV infection, and HIV-positive MSM will then be more likely to contract other opportunistic infections, e.g. fungal, viral, and bacterial. This risk will depend directly on the immunosuppression status of these patients ${ }^{20}$. Social determinants will also be part of the recrudescence of the disease or the strengthening of the health of these individuals. Therefore, understanding diseases in particular groups will require knowing and "realizing" the disease from another perspective ${ }^{21}$.

In the case of HIV-positive MSM that we evaluate, we determine candidiasis as the most frequent opportunistic infection, independently of the use of HAART, the time between the basal HIV-infection and the fungal infection, and the immune function (CD4+ lymphocyte and viral load). Our findings have shown that candidiasis is cosmopolitan and can affect various organic structures (Table 1).

Although our candidiasis reports agree with previous studies $^{3,4,22}$, it seems that HAART is not being effective in reducing these infections as previously reported ${ }^{23}$. Other socio-epidemiological components must be influencing for progressive contagion in these patients that should be determined in future studies in order to understand, not only why they get infected with opportunistic microorganisms, but also to understand the social context that is the key point for achieve to improve the quality of life of these subjects.

On the other hand, we did not find a mucocutaneous infection preference within candidiasis. Our findings disagree with other studies that have placed oral candidiasis as the most frequent ${ }^{20,24}$. Maintaining this species as the main opportunistic fungus could be due to the emergence of new species (non-albicans) that are preferably infecting subjects with more accessible profiles, such as HIV-positive patients.

After opportunistic fungal infections, our data places a huge isolate of dermatophytes as Tinea pedis and Tinea corporis as the most frequent superficial agents. These infections by dermatophytes must be adequately considered in patients with HIV where they tend to compromise tissues due to the immunosuppression of the subjects and to high viral loads ${ }^{25,26}$. Although global rates of resistance have not yet emerged, there are sporadic reports that in perspective describe the antifungal resistance phenomena of these agents, which are the most common infections in both immunocompromised and immunocompetent patients ${ }^{27}$.

This study had limitations. Firstly, our preliminary results do not represent the total nationwide frequency of opportunistic and superficial fungal infections in HIVpositive patients, since the study was aimed at MSM/ WSW patients of HNGAI. Another limitation was that the antifungal susceptibility profiles of the isolated species were not determined. At this moment, our team has been working on this subject, having determined a 35\% resistance rate for fluconazole and voriconazole in Candida species (personal communication - JMS). These data could situate the isolated species in these immunocompromised subjects up to three-fold more than previous reports of antifungal resistance in Candida species ${ }^{28}$.

It has been shown that immigrants and refugees who originate in areas where infections persist can represent an important challenge for control disease national-healthstrategies $^{29}$. The results presented in this manuscript have no pretension other than to present data on the frequency of fungal opportunistic infections in HIV-positive patients, however, well-considered positions could estimate their future impact, and their oscillation under certain current socio-epidemiological factors, as for example after the establishment of the Venezuelan "refugee" community in Peru.

The migratory crisis that has generated the breakdown of the Venezuelan state represents a challenge for the South American region. Although we contextualize in this manuscript the problem of risk factors as a possibility in the fluctuation of HIV infection, this latent state of sanitary deterioration could be estimated for other risk groups. Since for more than three years the republic of Venezuela does not have an organized system of Public Health ${ }^{30}$.

Consistent with the current Venezuelan National Hospital Survey has shown ${ }^{31}$, the dramatic decline of the Venezuelan health system has led to a general state of emergency, but mainly for infectious diseases that can be 
mobilized during forced migrations, as has been previously evidenced $^{32}$. This situation could increase morbidity and mortality rates of diseases prevalent in the region such as HIV and tuberculosis.

Furthermore, this situation demands on the one hand the validity of knowing the prevalent diseases that could transit to South American Countries mainly, with the purpose of educating all the health workers, alert the general community and the systems of prevention and control of diseases. And, in this way prevent transmission of these infections such as Venezuelan hemorrhagic fever, diphtheria, measles, onchocerciasis, malaria, ChagasMazza disease, among others ${ }^{26,33-35}$.

On the other hand, this situation leads us to claim the poor justified national political decisions for the massive entry of the Venezuelan population into Peru, without or with little sanitary control that surely, if not already, is an economic and social cost for the nation.

In Venezuela, high frequency of dermatophytosis $(60.5 \%)$ and pityriasis versicolor $(19 \%)$ have been reported as superficial mycoses, the paracoccidioidomycosis (33.9\%) and histoplasmosis (33\%) as systemic and invasive infections, and chromoblastomycosis (65\%) as deep localized mycosis ${ }^{36}$. Due to the high endemic level of these fungal infections, their role in HIV positive patients could be a challenge for the national health system. The casuistry of the National Health Institute has shown that the most frequent fungal infections are histoplasmosis, paracoccidioidomycosis and cryptococcosis ${ }^{37}$.

An outbreak of imported measles in the Peruvian province of Callao has recently been reported after 17 years, which has corresponded with the Venezuelan migrant population ${ }^{38}$. These contemporary migratory epidemiological components could favor fungal infection in seropositive patients. In this sense, epidemiological surveillance and HIV prevention health programs should focus on preventing opportunistic infections, even more so if they are MSM/WSW with a high risk of contagion due to their biological, sociocultural and behavioral determinants ${ }^{39,40}$.

\section{Conclusion}

This retrospective study conducted in MSM patients with human immunodeficiency virus (HIV) to determine the frequency of opportunistic infections caused by fungi showed more than forty percent of patients with infections mainly by candidiasis, pneumocystosis and cryptococcosis.

Finally, these preliminary results allow us to lay the basics for future studies, which provide a clinicalepidemiological framework for understanding the impact of this immigrant phenomena and infectious diseases, where we must gather information on the topic, as it could constitute a new challenge for the Peruvian Public Health system.

\section{Acknowledgments}

We appreciate the invaluable support and the cordial collaboration of the Clinical Histories Staff of the HNGAI for the support provided.

\section{References}

1. Webb B, Ferraro J, Rea S, et al. Epidemiology and Clinical Features of Invasive Fungal Disease in a US Healthcare Network. Open Forum Infect Dis. 2017; 4(Suppl 1): S83.

2. Colombo AL, Tobón A, Restrepo A, et al. Epidemiology of endemic systemic fungal infections in Latin America. Med Mycol. 2011; 49: 785-798.

3. Limper AH, Adenis A, Le T, et al. Fungal infections in HIV/AIDS. Lancet Infect Dis. 2017; 17(11): e334-e343.

4. Armstrong-James D, Meintjes G, Brown GD. A neglected epidemic: fungal infections in HIV/AIDS. Trends in Microbiol. 2014; 22(3): 120-127.

5. Bustamante B, Denning DW, Campos PE. Serious fungal infections in Peru. Eur J Clin Microbiol Infect Dis. 2017; 36(6): 943-948.

6. de Vries HJ. Sexually transmitted infections in men who have sex with men. Clin Dermatol. 2014; 32(2): 181-8.

7. Manderson L. Neglected Diseases of Poverty. Med Anthropol. 2012; 31: 283-286.

8. Bowen LN, Smith B, Reich D, et al. HIV-associated opportunistic CNS infections: pathophysiology, diagnosis and treatment. Nat Rev Neurol. 2016; 12(11): 662-674.

9. Fraree Silva R. Chapter 8 - Fungal infections in immunocompromised patients. J Bras Pneumol. 2010; 36(1): 142-147.

10. Ministerio de Salud. Norma técnica de salud de atención integral del adulto con infección por el virus de la inmunodeficiencia humana (VIH). Lima: NTS № 097-MINSA/DGSP-V-02, MINSA; 2014.

11. World Health Organization. Consolidated guidelines on HIV prevention, diagnosis, treatment and care for key populations - 2016 update. France: WHO; 2016.

12. Ministerio de Salud. Norma técnica para el tratamiento antirretroviral de gran actividad - TARGA en adultos infectados por el Virus de La Inmunodeficiencia Humana. Lima: NT № 004-MINSA/DGSP-V.02, MINSA; 2005.

13. World Health Organization. Laboratory manual for diagnosis of fungal opportunistic infections in HIV/AIDS patients. Geneva: WHO; 2009.

14. Substance Abuse and Mental Health Services Administration. Treatment Improvement Protocol (TIP) Series. No. 37. Rockville (MD): SAMHSA, Center for Substance Abuse Treatment (CSAT) for Persons with HIV/AIDS; 2000.

15. Bongomin F, Gago S, Oladele RO, et al. Global and Multi-National Prevalence of Fungal Diseases-Estimate Precision. J Fungi (Basel). 2017; 3(4): 57.

16. Zurita MS. Situación de la resistencia antifúngica de especies del género Candida en Perú. Rev Per Med Exp Salud Publica. 2018; 35(1): 126-31.

17. Eza D, Cerrillo G, Castro C, et al. Resultados post mórtem e infecciones oportunistas en pacientes VIH-positivos de un hospital público del Perú. Rev Per Med Exp Salud Publica. 2006; 23(4): 270-274.

18. Bava AJ, Cattaneo S, Bellegarde E. Diagnosis of pulmonary pneumocystosis by microscopy on wet mount preparations. Rev Inst Med Trop Sao Paulo. 2002; 44(5): 279-82. 
19. De Armas Rodríguez Y, Wissmann G, Müller AL, et al. Pneumocystis jirovecii pneumonia in developing countries. Parasite. 2011; 18(3): 219-228.

20. Anwar KP, Malik A, Subhan KH. Profile of candidiasis in HIV infected patients. Iran J Microbiol. 2012; 4(4): 204-209.

21. Ortiz P. Cuadernos de Psicobiología Social, 2nd Ed. Lima: Fondo Editorial de la Universidad de Ciencias y Humanidades; 2010.

22. Guinea J. Global trends in the distribution of Candida species causing candidemia. Clin Microbiol Infect. 2014; 20 Suppl 6): 5-10.

23. Armstrong D. Problems in management of opportunistic fungaldiseases. Rev Infect Dis. 1989; 11(Suppl. 7): S1591-S1599.

24. Singh A, Bairy I, Shivananda PG. Spectrum of opportunistic infections in AIDS cases. IntConf AIDS. 2003; 57: 16-21.

25. World Health Organization. Guidelines on the Treatment of Skin and Oral HIV-Associated Conditions in Children and Adults. Geneva: World Health Organization; 2014.

26. da Silva BC, Paula CR, Auler ME, et al. Dermatophytosis and immunovirological status of HIV-infected and AIDS patients from Sao Paulo city, Brazil. Mycoses. 2014; 57 (6): 371-6.

27. Martinez-Rossi NM, Bitencourt TA, Peres NTA, et al. Dermatophyte Resistance to Antifungal Drugs: Mechanisms and Prospectus. Front Microbiol. 2018; 9: 1108.

28. Moran GP, Sullivan DJ, Henman MC, et al. Antifungal drug susceptibilities of oral Candida dubliniensis isolates fromhuman immunodeficiency virus (HIV)-infected and non-HIV-infected subjects and generation of stable fluconazole-resistant derivatives in vitro. Antimicrob Agents Chemother. 1997; 41(3): 617-623.

29. Gushulak BD, MacPherson DW. Globalization of Infectious Diseases: The Impact of Migration. Clin Infect Dis. 2014; 38(12): 1742-1748.

30. Editorial. The collapse of the Venezuelan health system. Lancet. 2018; 391: 1331
31. Gabaldón JC. Venezuelan Hospitals' Condition Worsens: The 2018 National Hospital Poll. Caracas Chronices; 2018. Article online. [URL] Available on: https://www.caracaschronicles.com/2018/03/22/ venezuelan-hospitals-condition-worsens-the-2018-nationalhospital-poll/ Access: 10/10/2018.

32. Castelli F, Sulis G. Migration and infectious diseases. Clin Microbiol Infec. $2017 ; 23: 283-289$.

33. Pan American Health Organization. Epidemiological Update: Diphtheria. 29 August 2018. Washington, D.C. PAHO/WHO; 2018.

34. Villalba JA. The challenges of restructuring health care in Venezuela. Lancet. 2018; 392(10144): 278-279.

35. Recht J, Siqueira AM, Monteiro WM, et al. Malaria in Brazil, Colombia, Peru and Venezuela: current challenges in malaria control and elimination. Malar J. 2017; 16: 273.

36. Martínez MD, Hernández VR, Alvarado $\mathrm{P}$, et al. Las micosis en Venezuela: casuística de los Grupos de Trabajo en Micología (19842010). Rev Iberoam Micol. 2013; 30(1): 39-46.

37. Reviákina V, Panizo M, Dolande M, et al. Micosis profundas sistémicas: Casuística del Departamento de Micología del Instituto Nacional de Higiene "Rafael Rangel” durante 5 años (1997-2001). Rev Soc Ven Microbiol. 2002; 22(2): 164-168.

38. Ministerio de Salud. Actualización Alerta Epidemiológica AE0102018. Riesgo de introducción y circulación del virus de sarampión debido a casos importados Perú. Lima: AE-CDC-No 009-2018, MINSA; 2018.

39. Joint United Nations Programme on HIV/AIDS. Miles to go: closing gaps, breaking barriers, fighting injustices. Switzerland: Global AIDS update, UNAIDS; 2018.

40. Beyrer C, Baral SD, van Griensven F, et al. Global epidemiology of HIV infection in men who have sex with men. Lancet. 2012; 380(9839): 367-377. 